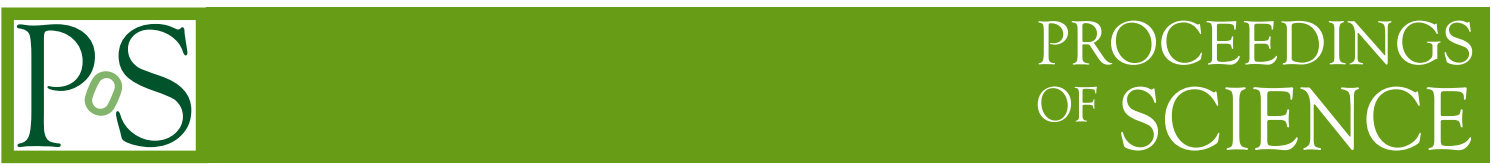

\title{
Art and Physics
}

\author{
Nikola Godinovic ${ }^{* \dagger}$ \\ University of Split, Faculty of Electrical Engineering, Machine Engineering and Naval \\ Architecture \\ E-mail: nikola.godinovicefesb.hr
}

This essay about art and physics is the result of myself education in the history fine art, since I wanted to understand by myself why some artworks are masterpiece and other are not. Reading art history books, have noticed that there is an inextricable link between art and science, which will be discussed here. Namely, the spirit of time, (zeitgeist) of certain epoch is defined by the science, while art interprets it, provokes it ans holistically sublimates in the artwork reflecting the narrative of the certain period, but also sometimes rejecting the current narratives and creating the new one. After public lectures to art students and their professors about link between art and physics, which were very well received, I continued to deliberate about it. One of the outcome, is the exhibition of the artworks done by the fine art students in Split, inspired by various physical concepts, which I tried to explain through a set of lectures. Science and art define the culture of an society, through intention to understand the world around us. Both, art and science develop the ability of abstract thinking, the most powerful tool of knowledge. Creativity is common to both science and art, science teaches us to think in a new way, and art teaches us to observe and perceive the world differently. Art seeks to understand what is that what govern us human and science what is that what govern the natural phenomena. Intention of this essay is to point out that the knowledge of physics about the nature of space and time and the new scientific paradigm influenced also the artistic expression. Future will be shaped by new emerging technology advancing rapidly in an unpredictable way and there is jeopardy that deep emotion is replaced by a superficial impression and deep thinking is reduced to the use of "smart" applications. The science and art are the only guarantee to preserve those values of which our humanity and uniqueness of human beings are weaved. The purpose of education should not be a mere acquiring of skills needed by labour market, the main purpose of education is learn people how to think and make conclusion which leads to the new knowledge and constant questioning of the current knowledge.

European Physical Society Conference on High Energy Physics - EPS-HEP2019 -

10-17 July, 2019

Ghent, Belgium

\footnotetext{
* Speaker.

${ }^{\dagger}$ This work is partially supported by Centre of Research Excellence for Data Science and Advanced Cooperative Systems
}

(c) Copyright owned by the author(s) under the terms of the Creative Commons Attribution-NonCommercial-NoDerivatives 4.0 International License (CC BY-NC-ND 4.0).

https://pos.sissa.it/ 


\section{Introduction}

Even before our predecessors have learned to speak and have developed the ability of articulate speech, they started to paint on the cave walls. One could say that they wanted to convey message to the other intelligent beings, I was here in this cave, hoping that some intelligent beings will be able to understand their images. Actually to tell them you are not alone. This cave painting could be considered as an attempt to transfer the knowledge. The modern humans also send the painting to the extraterrestrial intelligent beings, mounted on the Pioneer 10 and Pioneer 11 spacecraft, launched in 1972, respectively 1973.
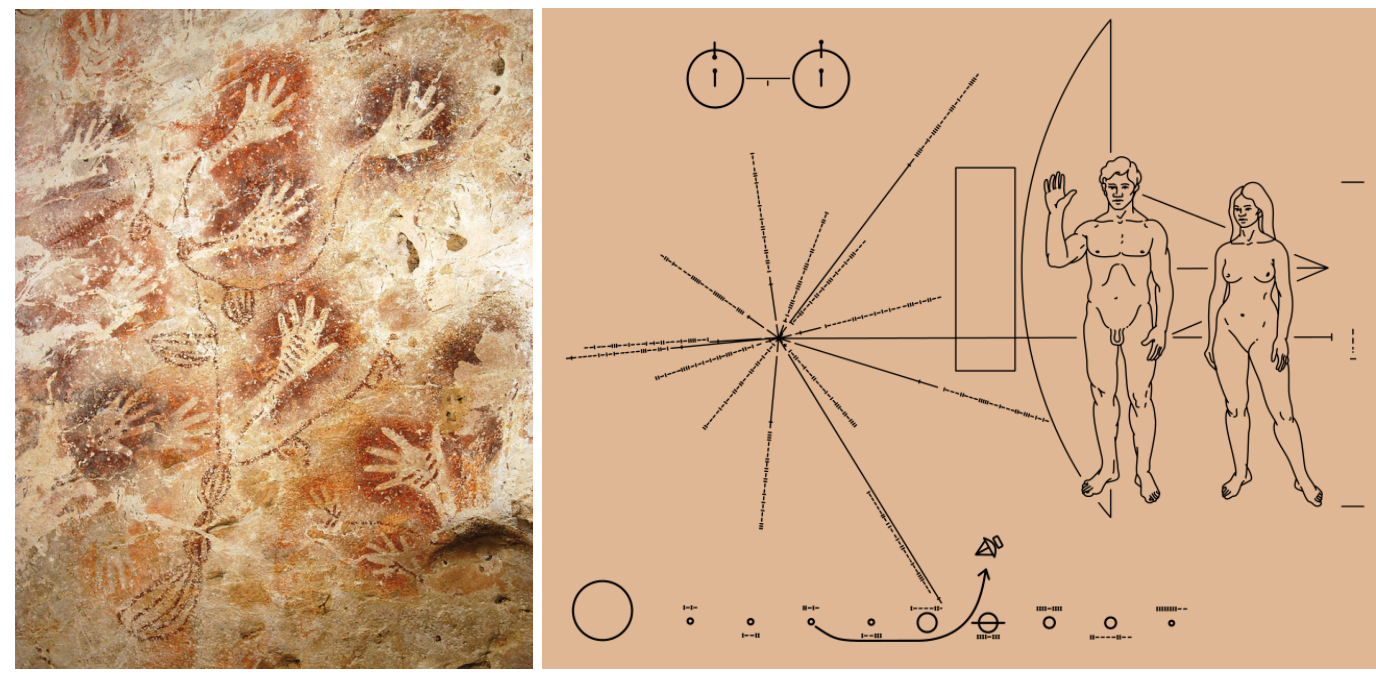

Figure 1: Left:cave painting, Right:The plaque attached to Pioneer 10

The plaques on Pioneers spacecrafts, show the pictorial message explaining that it was created by humans, which live on third planet around the Sun (our star), whose relative position in respect to the centre of our galaxy is encoded in the image and also conveying message, that we understand the structure of the hydrogen atom the most abundant element in the universe. It is hard to understand why some people doubt about the purpose of the art, since the the need for an artistic expression is a powerful evolutionary tool since it develops the ability of abstract thinking. Actually the alphabet could be considered the most useful abstract art ever, of course together with the numbers. Namely, digging around one could find gold and diamonds, oil, ... but no one could dig up letters and numbers. The alphabet and number system are pure abstract art and the most useful abstract creation of mankind mind. To educate myself in the history of fine art and analysis of artworks discussed here are based on the nice review book, Written by an international team of artists, art historians and curators, tracing the development of art period by period, with the illustrated text covering every genre, from painting and sculpture to conceptual art and performance art [1]. To end the introduction, let me sate the simple equation: culture $=$ science + art.

\section{Hellenistic Art and Science}

About 2500 years ago in the ancient Greek, people started to use commons sense and logic to understand the nature, for the first time the subjective internal world of imaginations, dreams and 
fears, was separated from the outside objective world. Thales of Miletus (624-545 BC) was the first one, who bravely said, to understand the world/nature, there is no need to consults with gods on the Olympus, it is enough to use reason and logic. These simple thoughts, has defined the spirit of time, the mental framework which we modern human have inherited and I do hope still following it. This mindset is the legacy which has leaded us to the modern society. In antiquity, for the first time space and time has been measured. Euclid has published his textbook âĂİElementsâĂİ in which he use mathematics to describe the spatial relations, and thus, he is considered as the founder of geometry, the first mathematical discipline. This book is is one of the most influential works in the history of mathematics, serving as the main textbook for teaching mathematics. Worth to mention, that Eratosthenes only using the stick and cord measured with the astonishing precision the Earth radius. The zeitgeist defined by the ancient Greek scholars is clearly embodied in the art works of that time. Sculptor Polykleitos writes a treatise (Kanon) in which he defines the proportions of the human body as an aesthetic principle, encoding them using numbers/mathematics. Even to prove it, Polykleitos creates famous statue of the "Spear Bearer" and introduced contrapposto, to prove mathematically defined aesthetics principle in the classical antiquity (1000 BCE to 450 $\mathrm{CE}$ ). The flat space and uniform time flow is our everyday experience and so it is intuitively easy to accept and understand Euclidean postulates. Thus, the artworks of classical antiquity reflecting this mindset, are very realistic, easy to understand and interpret, since they are respecting the geometry of flat space defined by Euclid. In the flat Euclidean space two parallel lines never cross and the distant object are smaller. Classical antiquity based on reason and logic ended about $400 \mathrm{AD}$ when the Alexandrian library was demolished and its last librarian, a women scholar Hypatia was killed. This event is considered as the beginning of the Dark Middle Age which lasted for 800 years, till the Renaissance.

\section{Middle Age Art and Science}

The burning of the Library of Alexandria marked the beginning of the so called Dark Middle Age, whose zeitgeist is sublimate in the thought of Tertullian, the early christian philosopher: âĂİAfter Jesus has no curiosity, there is no research after the Gospel. Believe it and want nothing moreâĂİ. The dominant narrative of the middle age was to âĂIsave soulâĂİ, body is not important. Sticking to this narrative (mindset), the burning of the witches on the stake, actually meant their salvation. A horrible example, showing the power of narratives, arising from intellectual climate of certain epoch. Art of the middle age served the Christian religion to worship divine. Thus artworks are dominated by the spiritual and religious motives. In painting there is no more perspective and spatial relationship of the flat Euclidean space. Everything is subordinate to religion, art is used to worship god and promote religion, skill to show $3 \mathrm{~d}$ on canvas of $2 \mathrm{~d}$ is lost is not used any more in painting. The dominant mindset taught, that answers to all question were to be found in the Bible, the laws of reason and logic were dismissed from A.D. 400 to A.D. 1250. St Augustine the most influential thinkers of the medieval mind taught: âĂIIIt is enough for the Christians to believe that the only cause of all created things ... whether heavenly or earthly ... is the goodness of the Creator, the true one God. Euclid's smooths space became fragmented in the medieval paintings, lost its homogeneity and could no longer be measured, no more perspective which shows the proper spatial relationship between the painted objects. It is impossible to comprehend the proper spatial 
relationship, earthly space unimportant, profane to be shown on paintings. Also the time was not properly shown, it is impossible to see which part of the day is on painting. In medieval art space and time have lost its physical meaning as concepts which could be comprehended and measured and used to express the spatial and temporal relationship according to common sense. Divine space and time are sacred and earthly space and time are profane and should no be matter of artwork. In Europe from 800 up 1300 A.D., for five centuries no layperson, from kings and emperors downward could read or write, illiteracy was norm. Although the masterpieces of the artwork, particularly in the architecture of the church's build in the middle age, show remarkable engineering achievements and some painting techniques and mosaic construction has been perfected, it is justified to call this period of human history as the "dark" middle age, since it was time when there were no new thoughts and knowledge, time of no curiosity.

\section{Renaissance Art and Science}

The first sign of the new mindset based on reason and logic, from which the renaissance will be born is seen in the Giotto di Bondone painting, since in his painting there are hint of perspective, the distant objects looks proportionally smaller. Giotto was the first who started to paint a scene as it is seen from a stationary point and in perspective, so that all lines of sight converge on the viewer's eye which is positioned in a stationary preferred location. This prospective technique creates the illusion of recession to nexal vanishing point. Nichole d'Oresme, around 1360, introduces a new tool, visual representation of numbers, the horizontal and vertical axis are used to show numbers obtained by measurements, graph - unavoidable tool in science ever since. Horizontal and vertical axis are used by painters to organise space on the canvas in agreement with the Euclidean flat space, In 1435. Leon Batista Alberti published his book "Della pittura" in which he elaborates the drawing technique of the perspective using strict mathematics and Euclidean geometry. By painting scene in perspective, means looking a scene from one stationary point of view, allowing artist to arrange three axes of space in their proper relationships (perspective means "clear-seeing"). Renaissance painting are realistic, almost as photography, preserving the the sizes, shapes and positions of various painted objects, relative to each other, as it is in the actual/real space. It is easy to understand and interpret the renaissance painting, everything looks reasonable, logical and does not contradict our intuitive understanding of the concept of space and time, which has been mathematically described by Euclidean postulates. The renaissance zeitgeist (mindset) is clearly visible in visual art, various technique to show 3-dimensional space on canvas 2-dimensional space has been introduced and perfected by various famous painters. The mindset seen in renaissance artworks, which reject middle age dogma, that everything should be subordinated by the divine worshipping, pave the way for the born of the modern scientific methods established by Galileo Galilei. Numerous renaissance artist were also researchers, the most famous one of course is Leonardo, struggled to understand various natural phenomena (vision, light, sound, ...) without divine interference. The renaissance mindset is sublimated very clearly in the Leonardo masterpiece the "Vitruvian Man" [2]. This remarkable Leonardo painting clearly proclaim that the "human" is the hero, that, we, humans could make the difference. Nice artistic explanation of the meaning of humanism, which was born after a lot of straggling. Flourish of science based on observation, reason and logic in the renaissance, was achieved by the work of 
the most prominent scientist (Nicolaus Copernicus, Giordano Bruno, Galileo Galilei, Marantun de Dominis,..) who taught us how to use scientific methodology to study nature and thus paved the way to the modern society. The renaissance artists and scholars, showed that the human by using mind and its most powerful tool, abstract thinking, could take destiny in his own hands. The most fundamental understating, at that time, of the nature of space and time culminated in the Newton laws of motion and gravity which have dominated the scientific reasoning till the begging of the twenty century. Newton taught about space: "Absolute space, in its own nature, without regard to anything external, remains always similar and immovable .." and about time: "Absolute, true and mathematical time, of itself, and from its own nature flows equably without regard to anything external ...".

\section{Modern Art and Science}

Invention of the photography by Joseph Nicephore Niepce in 1826, shacked the visual art community, so that French painter Paul Delaroche declared: "From today painting is dead" (what a wrong statement). In the same time, first half of the 19 century, mathematicians, Gauss, Lobachevsky and Riemann developed the new non-Euclidean geometry, geometry of curved space. Although the great mathematician Gauss already 1824 proposed a new non-Euclidean geometry, he never published it, probably because of fear to be ridiculed by colleagues. Simply because the mindset of that epoch, was that the Euclidean concept of space is inviolable. However, Lobachevsky was brave enough, to publish his theory of the geometry on curved space in 1840, stating among other that two parallel line could cross each other. The power of narrative arising from the zeitgeist was so dominant, that Lobachevsky has lost his professorship, because of his blasphemy against Euclid. But relatively soon, Einstein will show that actually space and time are indeed curved and that the concept of the absolute space and time dominating for centuries is simply wrong. About 20 years after the theory of curved space has been published, Eduard Manet, make his seminal painting "The Luncheon on the Grass" [3], which is considered as the first modern painting, since it is hard to understand, it does nor provide a clear message and does not respect all the existing canons of painting established in the renaissance. Educated physicist, actually could see that this famous Manet painting, encodes the geometry of the curved space. Namely, in the curved space the shape and size of the object depends where the object is placed in space. At the back part of this painting there is a lady figure which is huge according to the rules of the flat Euclidean space, illustrating the consequence of the curved space, that the size and shape of the object depends where it is placed in space. Of course, it is not fair to claim that Manet was familiar with the geometry of curved space, but there is a reasonable doubt, that Manet could be aware of the geometry of non-Euclidean geometry. Something which could be interested to investigate. This Manet painting is a nice example, which show that the breakthrough in art and science are born when the existing mental concepts, thought and narratives are questioned and mocked by artistic expression (mocking is the privilege of the artist and not of the scientists, who just have to show that the old theory is an approximation of the new theory). The special (1905.) and general (1915) theory of relativity demolished entirely the concept of the flat space and time ticking uniformly in the entire universe. Space and time are not any more untouchable stage at which physical phenomena taking places. In fact, space and time are affected by physical processes. Space and time are not two distinct 
concept, they are one entity, called "space-time", adjusting themselves in a way that the observer who is standing still and the other one who is chasing the light, must measure the same speed of light. Also the space-time is affected by the mass and energy which it contains. The more massive body makes space-time to "suffer" more, ie. making it to curve more. For light all the space is here and all the time is now, for light there is no space and time. The other amazing consequence of the new understanding of space-time that there are a region of space-time so curved due huge concentration of mass or energy that it is separated from the rest of space-time and we do not have a clue which physical laws are working inside this region of space-time called black hole. These new understanding of the concepts of space and time created a new spirit of time, a new narrative and mindset which is present in the art movements at the beginning of the 20 century. In that short period we have invented a new mental concepts about space-time and abstract physical quantities which make the foundation of quantum physics, like the quantum field. The quantum field is a pure construct of our mind, an abstract physical quantity which could not be measured, but, by using it, physicists are able to understand the nature at the atomic and subatomic level. The backbone of the modern technology are abstract concepts of the quantum physics, which are anti-intuitive since they are not part of our everyday experience. These new abstract physical concept shows the power of abstract thinking, which have created the zeitgeist sublimated in various fine art movements like: cubism, futurism, abstract art, conceptual art, performance ...etc. Famous painter Kandinsky [4] begin to explore the idea of art without image. Similarly as the physicists are looking for the most fundamental building entities of the universe (atoms, elementary particles ...) painter are also looking for the most fundamental substance of the painting. This spirit of time, looking for the most fundamental substance, could be seen in the abstract painting of Kazimir Malevich [5] and Jackson Pollock. The Pollock paintings, did not show "things" in the context of the homogeneous and linear space and time, but trying to seize "now", aiming to show the process of painting creation. It is interesting to remark, that actually the world which we experience, in which we live, is the results of the constant interactions of quantum fields ie. physical processes happening at the most fundamental level. The universe is in fact not made of elementary particles but of the quantum fields, which are the most fundamental substance of the universe. The elementary particle is a simple concept, having some position in space at certain time, some mass, charge and spin. On the contrary, the quantum filed is not localised entity, it exist everywhere in space at any time and we could not measure it. But we know how to provoke it, to show it existence by existing it, to create an elementary particle which we are able to measure. Thus by doing experiments at the LHC accelerator and using detector like CMS and ATLAS we have measured particle which is called Higgss boson and by detecting it, we have proved that Higgss quantum field exist together with other quantum field associated with the already discovered elementary particles, and that only those quantum fields associated with elementary particles having mass are interacting with Higgs quantum filed. At the end let me point to two artworks done by American artist Barnett Newman. One is the "Vir Heroicus Sublimis" (1950.), a huge canvas (2.5 m x $5.5 \mathrm{~m}$ ) [7], covered with single homogeneous colour of uniform texture and the only intervention in this monochromatic filed are few thin strips of contrasting colours. Having been educated as a physicist I see in this painting a quantum filed and its excitation's ie. elementary particles illustrated by the strips. Also the title of this Newman painting is very intriguing. Newman loved art passionately and continuously questioned it mission. For several years he debated what should be art and claim that: "The central 
issue of painting is the subject matter - what to paint". Looking at another Newman painting having title "The Dead of Euclid" (1942.) [8] is obvious why he gave this tile and it is a beautiful visual illustration of the demolishing of the concept of flat space what has been done by physics a years before.

\section{References}

[1] Stephen Farthing (Author, Editor), ART: The Whole Story, Quintesence (2012)

[2] https://www.leonardodavinci.net/the-vitruvian-man.jsp

[3] https://mymodernmet.com/edouard-manet-the-luncheon-on-the-grass/

[4] https://www.wassilykandinsky.net/painting1896-1944.php

[5] https://www.tate.org.uk/art/artists/kazimir-malevich-1561/five-ways-look-malevichs-black-square

[6] https://www.jackson-pollock.org/

[7] https://www.moma.org/collection/works/79250

[8] http://www.artnet.com/artists/barnett-newman/death-of-euclid-DYbA-a4E6cKUqT4a-gf44A2 